\title{
Scale Model Study of an Underground Opening in a Mine in Saudi Arabia
}

\author{
M. HANIF and M.A. DARWISH \\ Mining Engineering Department, Faculty of Engineering, \\ King Abdulaziz University, Jeddah, Saudi Arabia
}

\begin{abstract}
Physical scale model study of the mechanical behaviour of structures is of a vital importance in the design process and in the evaluation of performance of the prototypes. Important applications are in the fields of aeronautics, hydraulics, structural and mechanical engineering. It is also applied in mining engineering, particularly in relation to mine ventilation, the design of underground openings, evaluation of ground subsidence and slope stability.

Criteria for the scaling of physical quantities involved in the model study of the deformation behaviour of underground openings are developed. The mechanical properties of the rock mass around an underground mine opening are determined and the corresponding properties of an equivalent model material are also assessed. The technique of scale model testing is described and the results of the model tests are compared with those of the measurement of deformation of the actual opening.
\end{abstract}

\section{Introduction}

The stability of underground openings must have been of concern to man since he first started living in caves. The importance of ground control has tremendously increased relatively recently as modern mines have gone deeper; and wider openings are demanded due to ever increasing production, mechanization and demand for improved environmental conditions. The same applies to transportation, irrigation and drainage tunnels and caverns for underground facilities and storage. All these parameters and the need for safety, economy and advance planning have led to a var- 
iety of research activity in the field of stability and design of underground excavations. This is comprised of site investigation, mathematical analyses, computeraided numerical techniques and physical scale model studies.

A number of investigators have carried out tests on models of underground openings. Everling ${ }^{[1]}$ built two model test rigs, one for roadways and the other for coal faces at strength and geometric scales of 1:10. He simulated rocks by various mixes of portland cement, white alumina cement and quartz powder and simulated the stratigraphic planes of weakness as well as the supports. His tests were very successful. Hobbs ${ }^{[2]}$ worked out a number of scale factors for different physical quantities based on a geometric scale of 1:50 on the basis of Buckingham's Pi-theorem. However, it was practically impossible for him to conform to most of his rigid scales, e.g., strength and Young's modulus, 1:90, Poisson's ratio, 1:1, density, 11:20 and time, (1/ $50)^{1 / 2}$. In order to achieve such low strengths with plaster of paris-sand mixtures, he had to use excessive amount of water and dried the slabs in an oven at $90^{\circ} \mathrm{C}$. Hobbs' test rig was later used by Lawrence ${ }^{[3]}$. Whittaker and Hodgkinson ${ }^{[4]}$ used a much smaller geometric scale of $1 / 144$. His geometric scale was so small that the strength and other scales worked out by him from Buckingham's Pi-theorem would become difficult to strictly follow. Hanif ${ }^{[5]}$ developed a technique of scale model testing of underground openings using equivalent materials for rock, steel arches and rock bolts scaled down according to dimensionless numbers derived from first principles and based on the tensile strain criterion. As against the rigid strength scales required by the Pi-theorem, these numbers allowed a great deal of flexibility in the choice of model materials. He used a geometric scale of $1 / 30$ for his models of three different, actual situations in an underground opening in a coal mine. Kaiser and Morgenst$e^{e r n}{ }^{[6,7]}$ have used physical scale model tests on equivalent materials for the determination of time-dependent behaviour of small tunnels.

Scale model study can form an effective bridge between a theoretical or empirical design and full-scale field trials which would be much more expensive and time consuming.

An adequate amount of site investigation would be required to form a basis for the construction and testing of a physical scale model. For the purpose of the present study, a site was selected in the main decline of Mahd adh Dhahab gold mine, where site investigation and periodic measurements were made of the vertical and horizontal closure of the opening. An equivalent material scale model was built on the basis of the results of site investigation.

The results of the field measurement of deformation were found to be comparable with the amount of deformation measured for the model opening when the scaleddown equivalent load was applied to it. A further increase in load on the model helped predict the behaviour of the opening if it were located at a greater depth in a similar rock mass.

\section{Criteria of Simulation in the Scale Model}

The following modeling criterion is based on the requirement that for a similar be- 
haviour, strains in the model should be the same as the corresponding strains in the prototype. Assuming that stresses around a drift or tunnel are due to the weight of the superincumbent rock mass and let :

$F \quad=$ The total vertical force acting on the actual rock mass which is represented in the model.

$T_{\mathrm{o}}=$ Tensile strength of the rock.

$v=$ Poisson's ratio.

$\sigma=$ Principal stress.

$E=$ Young's modulus.

$L \quad=$ Length (any linear dimension).

$\epsilon_{t}=$ Tensile strain.

Assuming further that failure of the rock occurs due to tensile strain induced by compressive stresses which are caused only by the weight of the superincumbent rock mass, there will be an induced horizontal stress $K \sigma$ due to the strain occurring horizontally, where

$$
K=\frac{v}{1-v} \text { for an elastic medium }
$$

The net tensile strain will, then, be

$$
\left.\frac{\sigma}{E}\left(v+\frac{v^{2}}{1-v}\right) \text { or } \frac{\sigma v}{E} \text { (ignoring the term } \frac{v^{2}}{1-v}\right)
$$

If the actual tensile strain at failure $\epsilon_{t}=\frac{T_{\mathrm{o}}}{E}$, then the tensile strain due to compression

$$
\sigma \frac{v}{E}=\frac{F v}{L^{2} E}
$$

For a similar behaviour of the model and the prototype, the ratio between these must be the same, i.e.,

$$
\frac{F v}{L^{2} E} \div \frac{T_{0}}{E} \quad \text { should be the same, }
$$

or $\quad \frac{F v}{L^{2} T_{\mathrm{o}}} \quad$ should be the same.

The expression is dimensionless and may be called the Rock Strength Similarity Number, $N_{R}$. For a similar behaviour, this number must be the same for the model and the prototype.

The virtue of the number is that, given any geometrical scale, one does not have to stick to a particular strength scale. One may be varied independently of the other. All this would mean is that a different amount of force would need to be applied to the model. The difficulty, thus, experienced by Hobbs ${ }^{[2]}$ and Whittaker \& Hodgkin- 
son ${ }^{[4]}$ of attempting to achieve impracticable scales of physical and mechanical quantities for the model materials may be successfully overcome.

The equivalent force to be applied to the model with a given geometric scale may: be predicted by the similarity number.

If $L_{m} / L$ is the linear geometric scale, $T_{\mathrm{o} m} / T_{\mathrm{o}}$ and $v_{m} / v$ are the ratios of the tensile strength and Poisson's ratio, respectively, of the model and the prototype; $F$ is the force acting on the prototype and $F_{m}$, the corresponding force which must be applied to the model for the similar deformation behaviour, then

$$
\frac{F_{m} v_{m}}{L_{m}^{2} T_{\mathrm{o} m}}=\frac{F v}{L^{2} T_{\mathrm{o}}}
$$

The force to be applied to the model is, then, given by

$$
F_{m}=F \cdot \frac{L_{m}^{2} \times T_{\mathrm{o} m} \times v}{L^{2} \times T_{\mathrm{o}} \times v_{m}}
$$

\subsection{Simulation of Frictional Sliding on Joints}

The geometry of the joints should be simulated according to the geometric scale. Further, according to Coulomb's criterion, the resistance to shear stress, $\tau$ is provided by cohesion, $c$ a constant, and $\mu$ times the normal stress $\sigma$, thus

$$
\tau=c+\mu \sigma
$$

where, $\mu=\tan \phi$ and $\phi$ is the angle of friction of the material.

Cohesion may be simulated by using the rock strength similarity number. For filled joints suitable materials may be used in accordance with the scaling relationship. As for the friction angle $\phi$, it should be the same in the model as in the prototype, since its value depends on the ratio between the shear and normal stress which is dimensionless. Suitable materials may be used as coatings or fillings to simulate the value of $\phi$. A list of suitable coatings and fillings for various types of rock joints and fillings has been proposed by Fumagalli ${ }^{[8]}$.

\section{Design and Fabrication of Testing Equipment}

\subsection{Test Rig}

The testing rig was designed to test a two dimensional model. The criteria of simulation take care of the similarity of the body conditions of the model and the prototype. The boundary conditions of the modeled rock mass should also be satisfied as far as possible. A rectangular vertical plate of rock mass across the axis of the opening was modeled.

Various researchers have used different techniques for applying load to the model. Everling ${ }^{[1]}$, Hobbs ${ }^{[2]}$ and Kaiser \& Morgenstern ${ }^{[6]}$ used a number of hydraulic rams applying the same intensity of force on the top and bottom of the model. Whittaker 
and Hodgkinson ${ }^{[4]}$ used single platens on the top and bottom of his model. Hanif ${ }^{[5]}$ and Dhar et al ${ }^{[9]}$ employed spring loaded multiple platen arrangement to allow for a continuous redistribution of load as the deformation progressed. This may be more applicable to the coal measure rocks, where relatively large deformations take place with a continuous readjustment of stresses around the opening. Since the deformations in the present case were expected to be small, the use of spring loaded platens was not deemed necessary. It was, therefore, decided to use a simpler arrangement of uniformly distributed load using a set of four platens at the top, and the same number at the bottom of the model.

Considering the available facilities and resources, it was decided to use a geometric scale of 1:40. The cross section of the actual opening was $4 \mathrm{~m} \times 4 \mathrm{~m}$. The size of the model opening was, therefore, $100 \mathrm{~mm} \times 100 \mathrm{~mm}$. Figure 1 illustrates the vertical

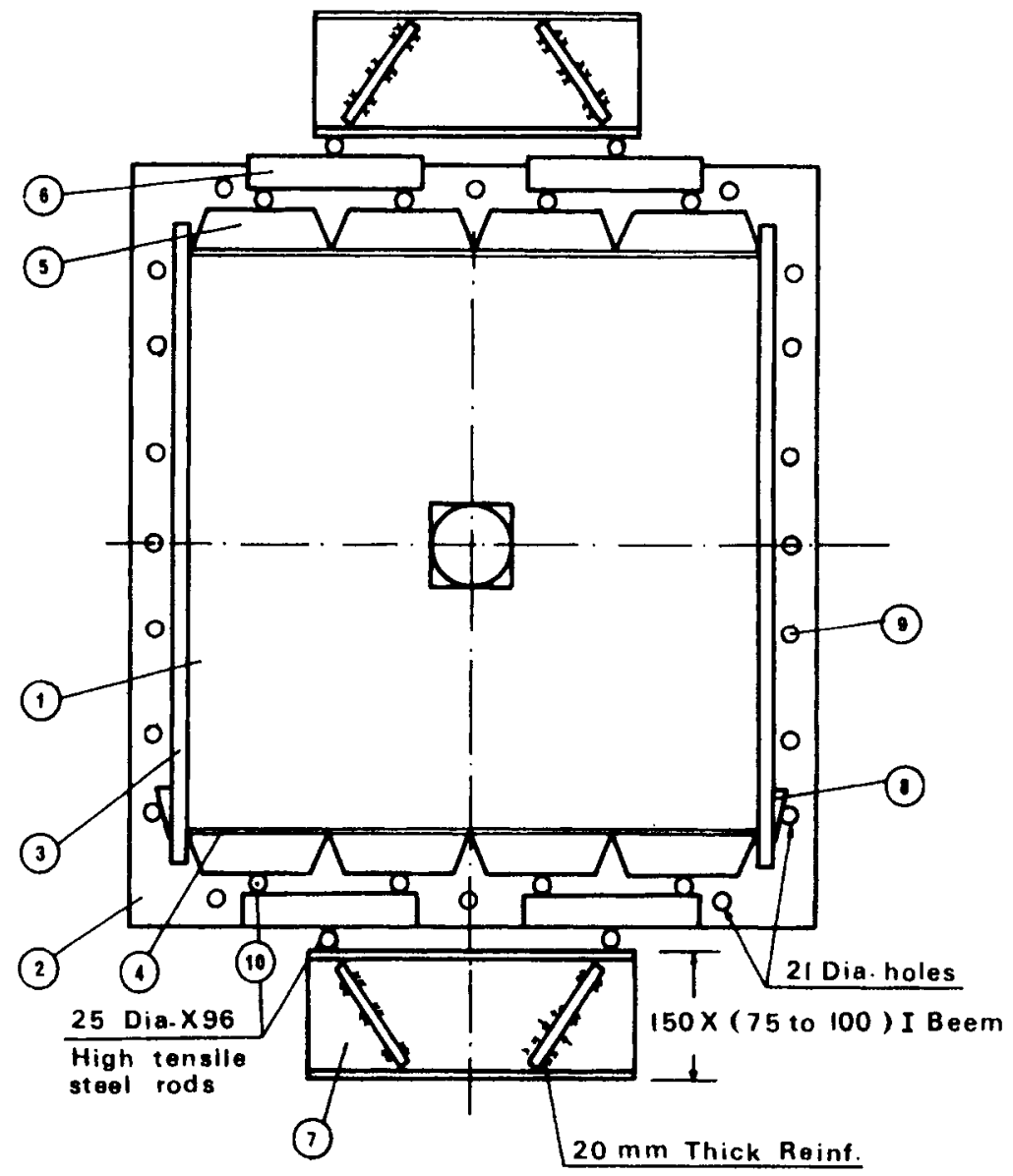

Key: (1) Model, (2) Back plate, (3) $20 \mathrm{~mm}$ thick side plate, (4) $1 \mathrm{~mm}$ thick stainless steel sheet, (5) Loading platen, (6) Plate beams, (7) Stiffened l-beam, (8) Wedges for end restraint, (9) Holes for $20 \mathrm{~mm}$ dia bolts for joining the front and back plates, (10) High tensile steel rollers.

Fig. 1. Vertical section through the model in the test rig. 
section through the model, and shows the loading arrangement. The front and back mild steel plates were $20 \mathrm{~mm}$ thick, stiffened with welded $25 \mathrm{~mm} \times 25 \mathrm{~mm}$ solid square bars. Two $20 \mathrm{~mm} \times 50 \mathrm{~mm}$ section welded yokes, each having a set of 3 studs for a front to back restraint of the model were provided as may be seen in photograph of the assembled test rig (Fig. 2). The front plate was provided with a central $225 \mathrm{~mm}$ $\times 225 \mathrm{~mm}$ square window, fitted with a $25 \mathrm{~mm}$ thick perspex plate, while the rear plate contained a $100 \mathrm{~mm}$ dia hole as an access for the instrumentation of the model opening. Two $20 \mathrm{~mm}$ thick mild steel plates were provided for the end restraint to the model. The side plates were supported against the model by a number of mild steel wedges between them and the bolts connecting the front and back plates.

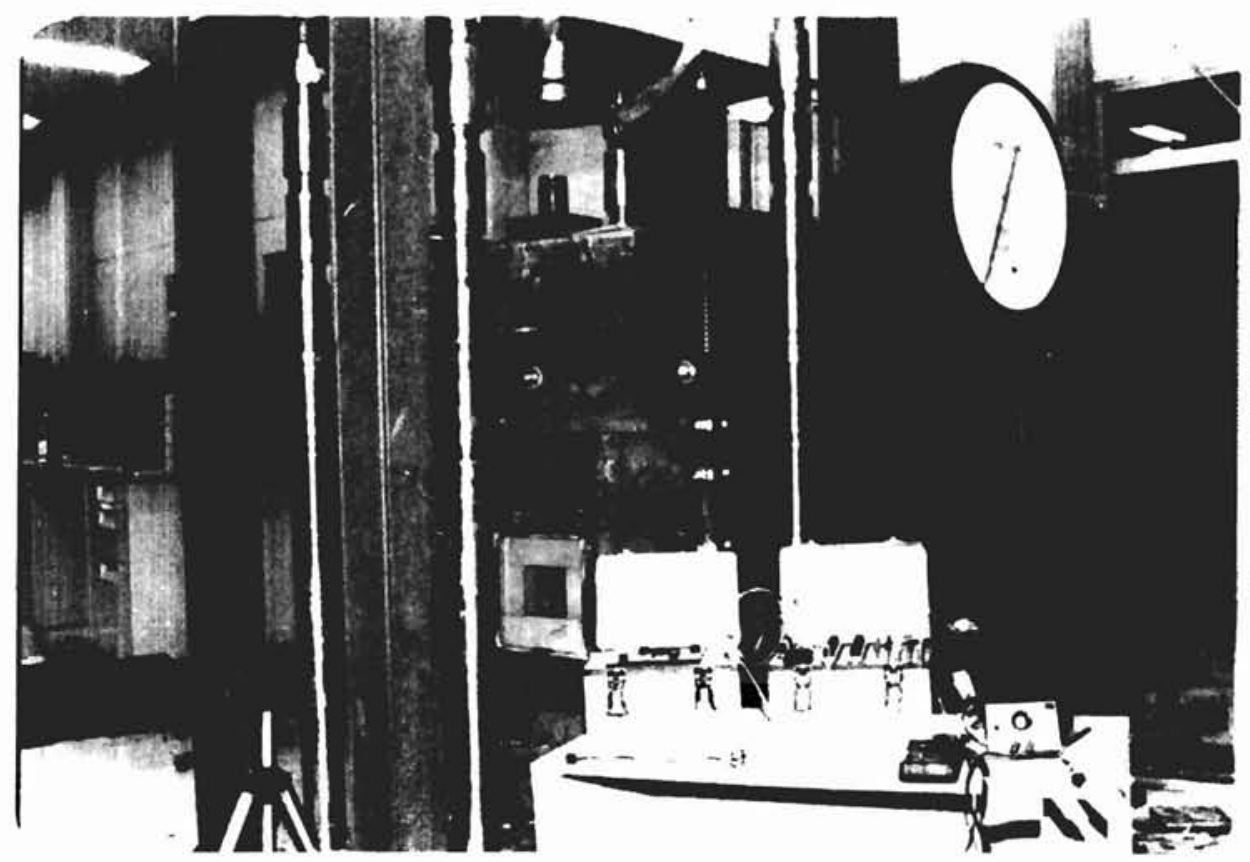

'FIG. 2. Model testing rig positioned in the 100 tonne Tinius Oluson testing machine; the monitoring instruments may be seen in the foreground.

\section{Collection of Data and Rock Testing}

A site was selected in the main decline of Mahd adh Dhahab gold mine, $370 \mathrm{~km}$ north east of Jeddah. The details of site investigation, which included data collection, rock core testing and measurement of ground deformation were reported ear$\operatorname{lier}^{[10,11]}$. The diamond drill core of borehole No. 167 was logged and a 20 metre length of the core was collected for laboratory testing. Representative samples of each metre length of core were subjected to the Brazilian and point load tests as indices of tensile strength. Stress-strain tests were performed on four specimens for the determination of Poisson's ratio and Young's modulus. Punch shear test, uniaxial 
compressive strength test and direct shear tests were also performed. A summary of the results of these tests is given in Table 1 .

TABLE 1. Results of laboratory tests on rock core of B.H. No. 167 at Mahd Adh Dhahab.

\begin{tabular}{|l|c|c|}
\hline Property tested for & $\begin{array}{c}\text { No. of } \\
\text { tests }\end{array}$ & Value \\
\hline Tensile strength (Brazilian). & 37 & $12.05 \mathrm{MN} / \mathrm{m}^{2}$ \\
Point load. Tensile strength index. & 42 & $10.28 \mathrm{MN} / \mathrm{m}^{2}$ \\
Punch shear test. & 28 & $48.60 \mathrm{MN} / \mathrm{m}^{2}$ \\
Uniaxial compressive strength, $C$. & 7 & $124.80 \mathrm{MN} / \mathrm{m}^{2}$ \\
Young's modulus, $E$. & 3 & $65.70 \mathrm{GN} / \mathrm{m}^{2}$ \\
Modulus ratio, $E$ C. & - & 526.00 \\
Poisson's ratio. & 3 & 0.27 \\
Angle of friction (direct shear test on saw-cut specimen). & 1 & $29^{\circ}$ \\
\hline
\end{tabular}

\subsection{Field Measurements}

At the selected site, just behind the face, four datum pins with stainless steel recessed insert at the open ends, were installed, one each in the roof, floor and either side. The vertical and horizontal closure was measured with the help of a specially fabricated stainless steel extensometer reading to a precision of $0.01 \mathrm{~mm}$. The horizontal and vertical closure after 50 days were $0.95 \mathrm{~mm}$ and $11.17 \mathrm{~mm}$, respectively. No further significant movement was observed after that period, suggesting that the opening had attained a stable state.

\section{Preparation and Testing of the Scale Models}

\subsection{Model Material}

White portland cement + sand mixture was selected as a brittle, rock-like material after trial with other materials. Various mixes of cement and sand, with just enought water for a proper consistency, were subjected to point load, Brazilian, punch shear and uniaxial compressive strength tests as well as tests for the stress-strain relationship. The proportion of water added in each case was recorded. The results of these tests are summarized in Table 2.

TABLE. 2. Results of test on various mixes of white cement and sand.

\begin{tabular}{|c|c|c|c|c|}
\hline $\begin{array}{lll}\text { Cement } & \begin{array}{l}\text { sand } \\
\text { ratio }\end{array} \\
\end{array}$ & $1: 1$ & $1: 1.5$ & $1: 2$ & $1: 3$ \\
\hline Brazilian tensile strength $\left(\mathrm{MN} / \mathrm{m}^{2}\right)$. & 3.67 & 3.78 & 277 & 195 \\
\hline Point load tensile strength $\left(\mathrm{MN} / \mathrm{m}^{2}\right)$. & 3.26 & 3.20 & 2.37 & 1.82 \\
\hline Compressive strength, $C\left(\mathrm{MN} / \mathrm{m}^{2}\right)$. & 33.39 & 26.00 & 24.36 & 13.39 \\
\hline Punch shear strength $\left(\mathrm{MN} / \mathrm{m}^{2}\right)$ & 13.40 & 13.26 & 11.40 & 6.91 \\
\hline Young's modulus@50\% of the stress at failure, $E,\left(\mathrm{GN} / \mathrm{m}^{2}\right)$. & 14.20 & 14.90 & 13.70 & - \\
\hline Modulus ratio, $E / C$ & 401.00 & 573.00 & 562.00 & - \\
\hline Poisson's ratio. & 0.22 & 0.22 & 0.21 & - \\
\hline
\end{tabular}


In all the cases, the specimens failed by brittle tensile fracture. The ratio of tensile (Brazilian) to compressive strength of the model material varied between 1:8 to 1:10, which was very close to the corresponding ratio for the rock; and so was the ratio for the Brazilian to punch shear strength of the modek, being quite close to the 1:4 ratio for the rock. The value of Poisson's ratio of the model material was around 0.22 at $50 \%$ of the final stress. This was somewhat lower than the corresponding value for the rock which averaged 0.27 . The Young's modulus/uniaxial compressive strength ratio for $1: 1.5$ and $1: 2$ mixes was very close to that of the rock.

\subsection{Casting of Model}

Rectangular beams were cast of the required mix using two mild steel moulds. The model was made up of four beams $150 \mathrm{~mm}$ high and one, $100 \mathrm{~mm}$ high. The latter was cut in suitable lengths to form the abutments and leave a $100 \mathrm{~mm} \times 100 \mathrm{~mm}$ square opening in the middle. Considering the capacity of the testing machine, the last two models were prepared by cutting the same set of beams in two halves. Various pieces of the model were joined together by a thin paste of plaster of Paris at the time of assembling the model.

\subsection{Instrumentation of the Model}

The instrumentation of the model was mainly comprised of a vertical and horizontal linear displacement transducer to measure the vertical and horizontal closure of the opening. A set of four strain gauges were also installed, one each in the roof and floor and either side to measure tangential strains. The transducers were carefully calibrated and monitored during the test using a digital multimeter. The strain gauges were read using a digital strain indicator and an accompanying 10 channel switching and balancing unit. Figure 2 shows the test rig set in position in a 100 tonne Tinius Oluson testing machine. The monitoring instruments may be seen in the foreground.

\subsection{Model Testing}

Three model tests were performed. Unfortunately, the results of the first test could not be accepted due to a malfunctioning of the load monitoring system of the loading machine. The second and third tests were conducted on two models which were prepared out of a set of beams cast with a 1:1.5 white cement: sand mix. The size of the model opening was $100 \mathrm{~mm} \times 100 \mathrm{~mm}$. A difference between the second and third test was in the method of providing end restraint. In the former test, this was done by inserting wedges between the side plates and the bolts joining the front and the back plates. In the latter case, a positive confinement was afforded through horizontal bolts by applying a calculated torque corresponding to each increment of load on the model on the basis of Poisson's ratio of the rock, the model material and the geometrical scale. The readings of closure and strain were taken at selected increments of load, and photographs were taken to record the appearance and development of cracks. 


\section{Results and Discussion}

The results of measurement of vertical and horizontal closure and tangential strains for tests No. 2 and 3 were plotted as deformation of the model opening and strains versus load on the model. Figure 3 shows such results for test No. 3. It may be seen from Fig. 3 that the slope of the vertical closure curve tends to gradually decrease as the load approaches a value of $450 \mathrm{kN}$, and then the slope abruptly increases. This point indicated the appearance of cracks in the roof and floor. A second major jump in the slope occurred at a load of $700 \mathrm{kN}$ when the sides also failed and the cracks in the roof and floor widened.

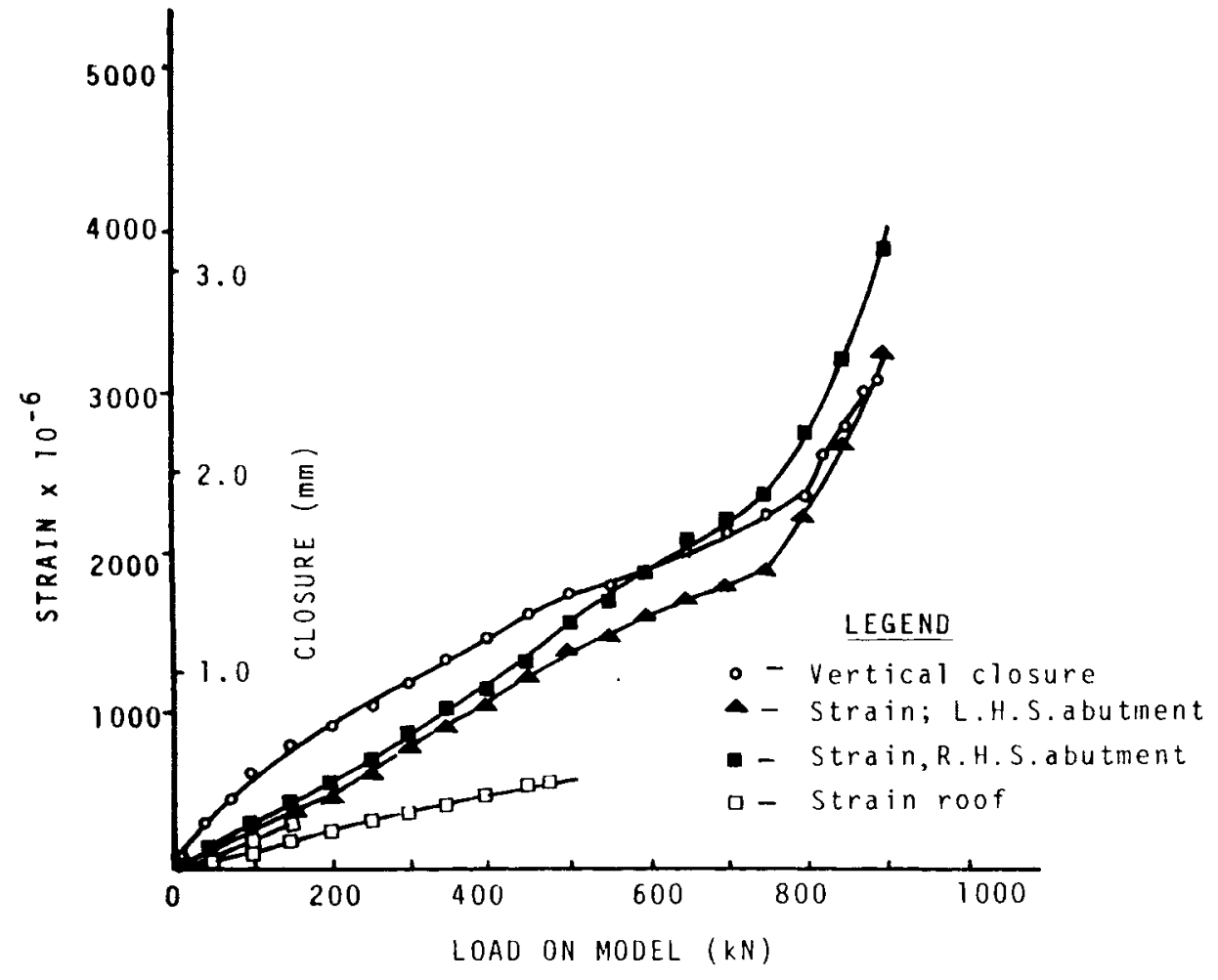

Fig. 3. Deformation and strains measured during scale model test No. 3.

Figure 4 is one of a series of photographs taken during test No. 3. It corresponds to a load of $800 \mathrm{kN}$ on the model and shows mid-span vertical cracks in the roof and floor as well as near-vertical curved cracks in the abutments. Oblique shear cracks may be seen in the left hand side top and bottom corners. Similar cracks on the right hand side appeared at a slightly higher load. The approximate location of the cracks is diagrammatically illustrated in Fig. 5.

\subsection{Comparison of Model Test Results with the Field Measurements}

The vertical closure in the main decline of Mahd adh Dhahab mine at a site $154 \mathrm{~m}$ 


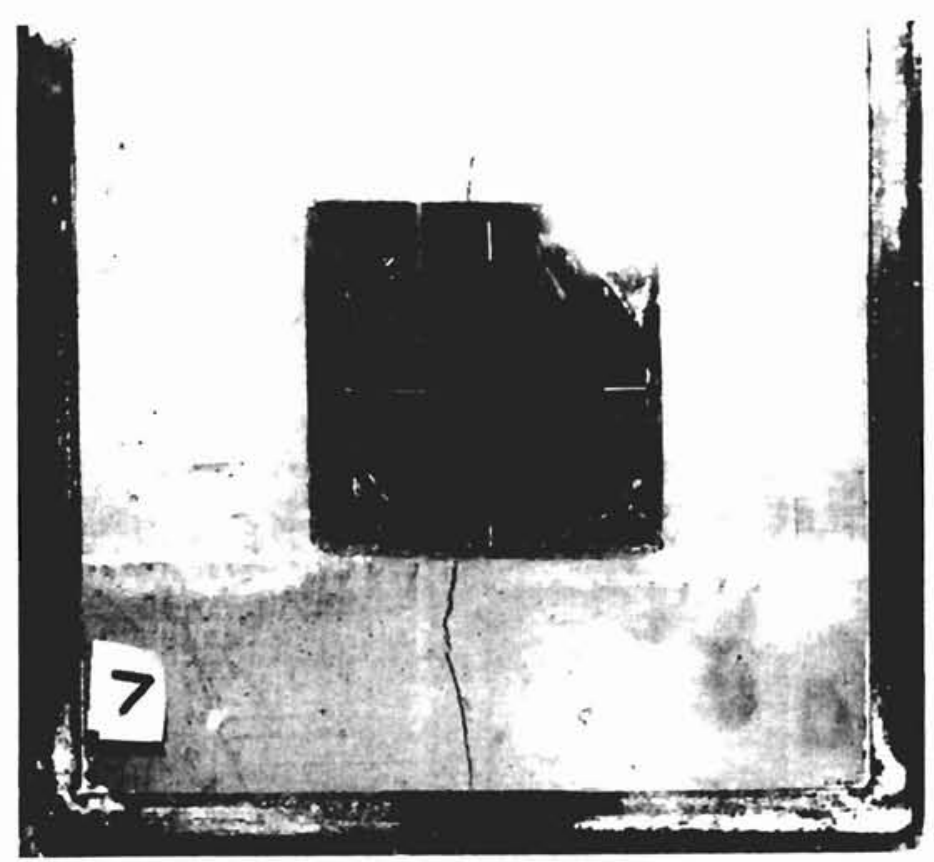

FIG. 4. Photograph taken at a load of $800 \mathrm{kN}$ during test No. 3 .

below the surface was measured as $11.7 \mathrm{~mm}$ in 50 days. The increase in the vertical closure for the next 180 days was only $0.31 \mathrm{~mm}$; suggesting that the opening was stable and required no support or reinforcement. When scaled down by the rock strength similarity number, the equivalent force on the model should be $45 \mathrm{kN}$. The vertical closure measured in the model at that load was $0.23 \mathrm{~mm}$ (from Fig. 3). When translated to full scale, this is equivalent to $9.2 \mathrm{~mm}$. This appears to be reasonably close to the vertical closure measured in the field.

The load of $45 \mathrm{kN}$ on the model is approximately $1 / 9$ th of the load at which first cracks appeared in the model. The overall failure of the model occurred beyond a load of $750 \mathrm{kN}$. This suggests that the depth at which tension cracks will appear in the roof and floor of a similar opening in an identical rock mass will be about $1350 \mathrm{~m}$ below the surface; and overall failure will not occur unless a depth of approximately $2500 \mathrm{~m}$ was reached. These depths are far beyond the presently planned depth of the mine. However, should the rocks be weaker at places due to weathering, faults, joints, shear zones or other structural weaknesses, difficulties may be expected at some of these places.

It may be important, therefore, to carry out engineering geological investigations on a routine basis in order to identify the areas where stability may be of concern.

\section{Conclusions}

1. Scale model testing may be used as a bridge between theoretical design of underground openings and their full scale construction. However, there is need to ob- 


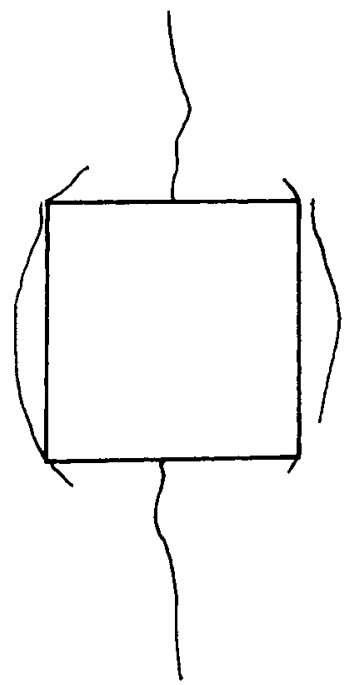

FIG. 5. A schematic sketch showing the position of cracks in the model at the end of model test No. 3.

tain an adequate geological and geotechnical information prior to the construction and testing of a realistic model.

2. The rock strength similarity number which is based on tensile strain criterion affords a flexibility in the choice of model material. This can make the design of a model simpler than the one based on Buckingham's Pi-theorem which requires a rigid scale to be followed for the properties of a model material.

3. The vertical closure measured in the actual underground opening was reasonably close to the one measured in the model opening when subjected to a load equivalent to that on the prototype due to the weight of the superincumbent rock mass represented in the model. The performance of the model was, therefore, quite satisfactory.

4. On the basis of the model test, it was predicted that first cracks in the roof and floor of a similar opening in an identical rock mass would not be expected until a depth of $1350 \mathrm{~m}$ was achieved and that an appreciable damage was not expected unless a depth of the order of $2500 \mathrm{~m}$ was exceeded. These depths are far greater than the planned depth of the mine. However, should the rock mass be weaker or locally weakened by weathering, water pressure or structural weaknesses such as joints, faults or shear zones, the optimistic picture predicted by the model test could be changed for the worse.

\section{Acknowledgement}

The authors gratefully acknowledge the financial support (Grant \# 407-095) of the Faculty of Engineering, King Abdulaziz University, Jeddah, Saudi Arabia, which enabled them to carry out the research work reported in this paper. Also acknow- 
ledged is the help provided by the management of Petromin in the course of field experiments in their gold mine at Mahd adh Dhahab.

\section{References}

[1] Everling, G., Model tests concerning the interaction of ground and roof support in gate-roads, Gluckauf, 98, (1960), Translation published in Int. J. Rock Mech. \& Min. Sci. 1: 319-326 (1964).

[2] Hobbs, D.W., Scale model studies of strata movement around mine roadways, apparatus, technique and some preliminary results, Int. J. Rock Mech. \& Min. Sci. 3: 101-127 (1966).

[3] Lawrence, D., Scale model studies of strata movement around mine roadways. - VII, Effects of vertical and horizontal pressures, Ini. J. Rock Mech. \& Min. Sci. 10: 173-182 (1973).

[4] Whittaker, B.N. and Hodgkinson, D.R., Influence of size on gate roadway stability, The Mining Engineer, January (1971).

[5] Hanif, M., Support and deformation of underground openings, Ph.D. thesis, Department of Mining \& Mineral Sci., University of Leeds, U.K. (1974)

[6] Kaiser, P.K. and Morgenstern, N.P., Time dependent deformation of small tunnels, I-Experimental Facilities, Int. J. Rock Mech. \& Min. Sci. \& Geomech. Abstr. 18(2) April: 129-140 (1981).

[7] Kaiser, P.K. and Morgenstern, N.P., Time dependent deformation of small tunnels, Il-Typical test data, Int. J. Rock Mech. \& Min. Sci. \& Geomech. Abstr. 18(2) April: 141-151 (1981).

[8] Fumagalli, E., Model simulation of rock mechanics problems, Rock Mechanics in Engineering Practice, in: Stagg, K.G. and Zienkiewics, O.C., Rock Mechanics in Engineering Practice, John Wiley \& Sons, reprinted (1979).

[9] Dhar, B.B., Ratan, S., Sharma, D.K. and Rao, P.M., Model study of fracture around underground excavations, Proceedings of Int. Symp. on Weak Rock, 1 (Sept.) : 267-272 (1981).

[10] Hanif, M. and Darwish, M.A., Scale model study of underground openings in jointed rocks, Final Report, Research Project, Faculty of Engineering, King Abdulaziz University, Jeddah, 407-095 (1988).

[11] Hanif, M. and Darwish, M.A., Deformation behaviour of an underground opening in a Saudi Arabian mine, Bulletin of the Faculty of Engineering, Assiut University, Egypt, 18 (part 1) January: 104110 (1990). 


\section{دراسـة نموذج بمقياس نسبي لفتحة تحت أرضيـة في منجم بالمملكة العربية السعودية}

\section{محمد حنيف و محمود علي درويش}

قسم هندسة التعدين ، كلية الهندسة ، جامعة الملك عبد العزيز

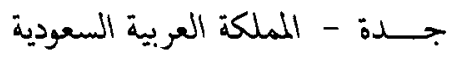

المستخلص . إن دراسة السلوك الميكانيكي للإنشاءات باستخدام الناذج الطبيعية ذات

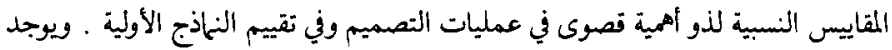

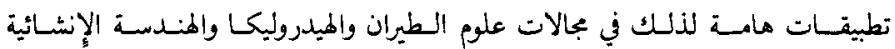

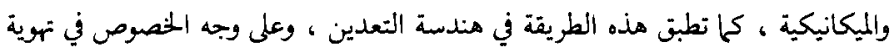

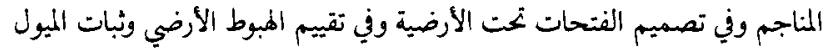

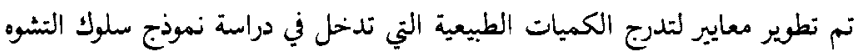

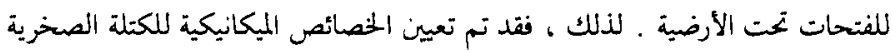

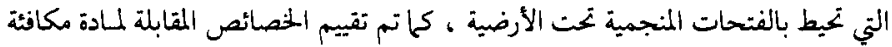

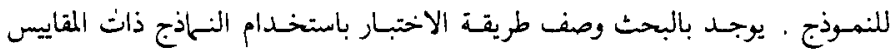

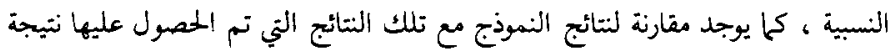
قياس التشوه لفتحة منجمية فعلية . 